\title{
Dimensões afetivas atualizadas no trabalho do Assistente Social
}

\author{
Updated affectionate dimensions in the work of the Social Worker
}

\author{
Sonia Vargas Mansano*
}

\begin{abstract}
Resumo:
Novas modalidades de trabalho vêm se destacando e se consolidando em nossa sociedade desde a segunda metade do século XX. Com isso, o trabalhador braçal, que disponibilizava o seu tempo e a sua força física para serem explorados pelo mercado, vem cedendo lugar ao trabalhador bem informado, que atua a partir do conhecimento, da resolução de problemas, da sociabilidade e do afeto. 0 Assistente Social, cuja intervenção está voltada para as relações humanas e suas dificuldades de inserção social, é um dos profissionais que segue essa tendência, executando aquilo que alguns autores denominam como "trabalho imaterial". Buscaremos analisar as dimensões afetivas que são atualizadas nessa profissão bem como as maneiras encontradas por esse trabalhador para acolher, analisar e elaborar as experiências, por vezes difíceis e limítrofes, que se fazem presentes em seu cotidiano.
\end{abstract}

Palavra-chave: Subjetividade; Trabalho; Afeto.

\begin{abstract}
:
New work modes are being consolidated in our society since the second half of century XX. The manual worker, that made available the time and physical force to be explored by the market, has been replaced by the very informed worker, that acts with the use of knowledge, problem resolution, sociability and affection. The social worker, whose intervention has gone back to the human relationships and their difficulties of social insertion, is one of the professionals that follow this tendency, executing what some authors call "immaterial work". We will analyze the affectionate dimensions that are present in this profession and the ways found by this worker to analyze and elaborate experiences, at times difficult and constrained, that are part of his daily work.
\end{abstract}

Key words: Subjectivity; Work; Affection.

* Doutora em Psicologia Clínica pela PUC/SP; Docente do Departamento de Psicologia Social e Institucional da UEL; E-mails mansano@uel.br 


\section{Introdução}

A Psicologia Social é uma área de conhecimento voltada para a compreensão do humano a partir das relações sociais. A abrangência de suas investigações é bastante ampla. Dentre elas, destacamos aqui as intervenções junto a instituições de diferentes tipos, a atuação nos movimentos sociais e políticos bem como a análise dos acontecimentos que produzem os mais variados efeitos na vida da coletividade. Na esfera do trabalho, especificamente, a Psicologia Social encontra uma oportunidade privilegiada de estudar uma dimensão da existência que, historicamente, passou a ocupar grande parte da vida da população. É sobre essa esfera que focalizaremos este estudo.

As relações profissionais sofreram diferentes modificações nas últimas décadas, em especial, com o avanço da tecnologia e do acesso a informações que, de diferentes maneiras, reorganizaram a cadeia produtiva. O século XX pode ser compreendido como um tempo histórico que possibilitou a invenção de novas modalidades de trabalho assim como a obsolescência de uma série de funções. Isso gerou diversas mudanças na natureza das relações estabelecidas entre o trabalhador e suas atividades, mas também colocou em destaque a questão dos vínculos sociais constituídos no cotidiano laboral.

O presente estudo busca investigar essas mudanças e analisar profissões de formação universitária que atuam diretamente com seres humanos, oferecendo-lhes, juntamente com a prestação de seus serviços, cuidados, atenção e afeto. Afinal, quais são as novas demandas que vêm sendo apresentadas para esses profissionais que dependem do contato social para realizar suas funções? Para avançar nesta investigação, acompanharemos os estudos de autores que fazem uso da noção de "Trabalho Imaterial" como Antonio Negri (2001), Michael Hardt (2001), Maurizzio Lazzarato (2001) e André Gorz (2005).

\section{Caracterizando o trabalho imaterial}

Negri (2001) assinala que as diferentes mudanças econômicas e tecnológicas desencadeadas nas últimas décadas do século XX, provocaram um deslocamento no foco do trabalho e nas estratégias de produção. Recorrendo a um breve retorno histórico podemos constatar que, desde a consolidação do capitalismo no século XVIII, a maior 
parte do trabalho humano era organizada a partir de atividades simples e repetitivas realizadas no interior das fábricas, tendo como objetivo a produção de bens materiais.

Naquele contexto, os trabalhadores eram submetidos a uma ampla carga horária de atividades. Deles era exigida, basicamente, a força física e um modo de subjetivação obediente, a partir do qual as normas e as metas de produção eram cumpridas num ritmo bastante acelerado.

Obviamente, esse modo de existir como "trabalhador obediente" não se consolidou de maneira rápida. Uma série de instituições, denominadas por Michel Foucault (1999) como "instituições disciplinares", participaram ativamente desse processo promovendo a disseminação e a naturalização de regras disciplinares a partir das quais era possível manter cada trabalhador numa função e num espaço bem definidos. Tendo como objetivo o aprimoramento da esfera profissional, Foucault ressalta que todo um conjunto de mecanismos diversificados foi colocado em funcionamento para que o homem acolhesse o trabalho como uma atividade central que organizava a sua existência. Para viabilizar esse empreendimento, Foucault diz:

\footnotetext{
É preciso que o tempo dos homens seja oferecido ao aparelho de produção; que o aparelho de produção possa utilizar o tempo de vida, o tempo de existência dos homens. É para isso e desta forma que o controle se exerce. São necessárias duas coisas para que se forme a sociedade industrial. Por um lado é preciso que o tempo dos homens seja colocado no mercado, oferecido aos que o querem comprar, e comprá-lo em troca de um salário; e é preciso, por outro lado, que este tempo dos homens seja transformado em tempo de trabalho (FOUCAULT, 1999, p. 116).
}

Assim, os séculos XVIII e XIX foram decisivos para consolidar essa organização social fabril que se apropriava do corpo e do tempo dos homens, dirigindo sua energia física para o aumento da produção material. Os efeitos da organização social disciplinar estão presentes até hoje na vida do trabalhador, em especial, no contexto brasileiro onde esse tipo de atividade é predominante.

Porém, quando analisamos as transformações do trabalho no século $\mathrm{XX}$, percebemos que novas forças entraram em cena provocando uma reorganização no processo produtivo. O avanço econômico e tecnológico, vivido especialmente após a Segunda Guerra Mundial, possibilitou a criação de novos postos de trabalho que são ligados, por um lado, ao gerenciamento de sistemas integrados da produção e, por outro, 
à oferta de serviços de diferentes tipos tais como aqueles voltados ao lazer, à educação, à cultura e à informação. Isso gerou a necessidade de profissionais diferenciados que apresentassem habilidades e conhecimentos específicos para atender as demandas sociais que se configuravam diferentemente.

Negri (2001) destaca, ainda, que o crescimento e a consolidação desses novos postos de trabalho já não exigem mais exclusivamente a exploração da força física do trabalhador empregada na fabricação de bens duráveis. Nos últimos anos, assistimos ao crescimento acelerado de um tipo de produção que, segundo esse autor, gera "um bem imaterial, como serviço, produto cultural, conhecimento ou comunicação" (NEGRI, 2001, p. 311). Entramos, assim, num tempo histórico no qual o trabalho de tipo imaterial se consolida cada vez mais fortemente na economia nacional.

Nos estudos de Negri e Hardt (2001, p. 314) podemos encontrar a descrição de três campos que caracterizam a atividade imaterial:

\footnotetext{
O primeiro está envolvido numa produção industrial que foi informacionalizada e incorporou tecnologias de comunicação de um modo que transforma o próprio trabalho de produção. A atividade fabril é vista como serviço, e o trabalho material da produção de bens duráveis mistura-se com o trabalho imaterial e inclina-se na direção dele. O segundo é o trabalho imaterial de tarefas analíticas e simbólicas, que se divide na manipulação inteligente e criativa de um lado e nos trabalhos simbólicos de rotina do outro. Finalmente, a terceira espécie de trabalho imaterial envolve a produção e a manipulação de afetos e requer contato humano (virtual ou real), bem como o trabalho do tipo físico.
}

Examinemos cada uma das modalidades do trabalho imaterial circunscritas pelos autores. Primeiramente, as tecnologias de comunicação. Em larga medida, elas definem as possibilidades de inserção das empresas ou dos profissionais no mercado de trabalho que se orienta cada vez mais pelo acesso e pela administração da informação. $O$ diferencial deste tempo histórico é que o acesso à rede informacional não é mais exclusividade de uma gerência, de uma instituição ou de áreas profissionais consideradas como mais sofisticadas e qualificadas. Cada um dos trabalhadores precisa e pode conectar-se a uma base informacional em constante ampliação e esse conhecimento torna-se primordial na realização da tarefa para a qual ele foi contratado. Com isso, aquele trabalhador que, anteriormente, ocupava-se apenas de atividades repetitivas, sem necessariamente ter acesso a algum conhecimento sobre o processo de produção ou 
sobre o produto final, agora é solicitado a conhecer os mínimos detalhes da cadeia produtiva e a colaborar para seu aperfeiçoamento, expondo suas percepções e opiniões ainda que, em muitos casos, elas não tenham as características de um saber técnico.

Percebe-se que o conhecimento baseado na experiência (que é vivida dentro e fora do cotidiano laboral) ganha importância e passa a ser valorizado. É nesse sentido que os autores, aqui mencionados, enfatizam o quanto o trabalho imaterial também se faz presente em atividades que, outrora, eram majoritariamente materiais, exigindo a resolução de pequenos problemas que emergem no cotidiano. Essa mistura (entre atividades materiais e imateriais), por sua vez, exige dos trabalhadores novas habilidades e conhecimentos.

O segundo tipo de trabalho imaterial, descrito pelos autores, está relacionado à manipulação inteligente e criativa das informações. Nesse caso, o foco não está apenas nos trabalhadores que, como vimos, são solicitados a intervir no processo de produção com sua experiência e seus conhecimentos. Todo um esforço é realizado para que também os usuários expressem suas opiniões sobre os produtos e os serviços consumidos. Para isso, diferentes informações são coletadas junto ao público consumidor e servem como ponto de partida para reorganizar a produção, sugerir a fabricação de novas mercadorias e melhorar as formas de distribuição. Assim, as empresas ou mesmo os profissionais liberais abrem-se cada vez mais para os contatos externos e a população em geral passa a intervir mais frequentemente nos processos de produção de mercadorias e serviços podendo, até mesmo, alterar o ritmo e a qualidade das atividades produtivas.

Entra em cena, aqui, uma outra esfera do trabalho imaterial que engloba a indústria do marketing. Esta se ocupa, primeiramente, em criar "mundos" subjetivos que serão associados às mercadorias ou aos serviços e que servirão para viabilizar uma adesão do usuário. É aí que podemos compreender como o consumidor assume um lugar importante no processo de produção. É somente ao identificar-se com esses "mundos", geralmente idealizados pelas campanhas publicitárias, que o indivíduo adere a eles e consome as mercadorias (LAZZARATO, 2001). Isso requer uma proximidade crescente das empresas e dos profissionais para com o público consumidor, visto que as mercadorias ou serviços oferecidos precisam fazer parte das suas aspirações e desejos. 
Por fim, os autores descrevem os trabalhos de tipo afetivo, sendo esse o maior interesse do presente estudo. O contato social é a base dessa atividade. Claro que toda a formação técnica continua sendo indispensável para garantir o bom desempenho de qualquer área profissional. Porém, no campo do trabalho imaterial afetivo, a técnica divide espaço com o exercício de outras habilidades, consideradas de ordem subjetiva, como o contato social, a comunicação, a capacidade de persuasão, o acolhimento, a sensibilidade e a atenção dirigida a outras pessoas.

Negri e Hardt (2001, p. 313-314) dizem que os resultados obtidos nesse tipo de trabalho são intangíveis por gerar "um sentimento de conforto, bem-estar, satisfação, excitação ou paixão". Nota-se, então, que o trabalho imaterial de tipo afetivo tem como ponto de partida o contato social. Isso pressupõe o acolhimento da presença viva do outro, que comparece na relação profissional expondo suas diferenças, expectativas, limites e potencialidades. Áreas profissionais que até bem pouco tempo eram identificadas como mais técnicas e objetivas, começam a visualizar a importância do contato social e afetivo a ser mantido com os clientes e o quanto isso interfere na qualidade e no resultado dos serviços prestados. Constata-se, assim, que o trabalho afetivo ganha uma nova importância no cenário econômico.

\section{Trabalho imaterial e Serviço Social}

Diversas são as áreas profissionais de formação universitária que estão ligadas à produção imaterial e afetiva. Ao tomarmos em análise, especificamente, as atividades exercidas por um Assistente Social, foco do presente estudo, nota-se que estamos diante de uma profissão criada recentemente e que acompanha à risca a descrição feita por esses autores. Trata-se de uma área cujo foco está na produção de conhecimentos voltados para a ampliação da proteção social, o que, por sua vez, implica na realização continuada de contatos sociais.

Suas intervenções têm por objetivo a elaboração de diagnósticos, a implementação de projetos para atuar junto à questão social e a operacionalização de serviços que supram as necessidades apontadas nos referidos diagnósticos. Mas este é apenas o ponto de partida. 
Gilles Deleuze, no prefácio da obra "A polícia das famílias" de Jacques Donzelot (1980), já chamava a atenção para um tempo histórico que experimenta intensamente o que ele chama de "ascensão do social". Como podemos compreender essa ascensão? Analisando o século $X X$, percebe-se o quanto ele foi marcado por confrontos de diferentes tipos que trouxeram consequências nefastas para a vida social como, por exemplo, as duas guerras mundiais. Paralelamente, acompanhamos o crescimento populacional acelerado, a expansão do espaço urbano bem como a necessidade crescente de atentar para os problemas que aí eram gerados.

Isso exigiu a elaboração de uma forma de governo mais extensiva, capaz de englobar o conjunto populacional que se tornava cada vez mais numeroso e díspar. Uma estratégia utilizada foi a criação de áreas profissionais qualificadas que deveriam intervir diretamente nos problemas sociais que eclodiram na complexa relação entre a população e o Estado. Deleuze descreve parte desses problemas quando comenta:

\footnotetext{
$O$ social tem por referência um setor particular em que se classificam problemas na verdade bastante diversos, casos especiais, instituições específicas, todo um pessoal qualificado (Assistentes "sociais", trabalhadores "sociais"). Fala-se de chagas sociais, do alcoolismo à droga; de programas sociais, da reprodução ao controle da natalidade; de desadaptações ou adaptações sociais (do pré-delinqüente, do indivíduo com distúrbios do caráter ou do deficiente, até os diversos tipos de promoção) (DELEUZE apud DONZELOT, 1980, p. 1).
}

Os trabalhadores que atuam junto ao social, no entendimento desse autor, compõem um campo profissional que se ocupa dos diferentes problemas que emergem a partir do aumento populacional das cidades e da dificuldade de administrá-los. Assim, a necessidade gradativa de elaboração de políticas de gestão para as cidades cooperou para criar e desenvolver áreas de conhecimento especializadas nas questões sociais. Pode-se notar que, em larga medida, a gestão estatal é realizada na parceria com esses profissionais, dentre os quais podemos citar os médicos especializados em saúde coletiva, os administradores, os psicólogos sociais, os criminalistas e os assistentes sociais.

Como poderíamos compreender a atuação do Assistente Social nesse contexto que marca a emergência do social como um problema de política pública? E, decorrente dessa primeira questão, como analisar as dimensões afetivas exigidas desse profissional na sua prática cotidiana? Um primeiro passo adotado nesta pesquisa consistiu em investigar as 
informações sobre esse curso superior nos documentos que são disponibilizados pela Universidade Estadual de Londrina. Nesse material, que é apresentado no catálogo de cursos desta instituição, encontramos a seguinte descrição:

O curso de Serviço Social pretende formar assistentes sociais capazes de intervir e construir conhecimentos numa perspectiva crítico-científica, considerando as demandas decorrentes da dinâmica da sociedade, do Estado e do próprio Serviço Social. Para isso, oferece instrumentos para levar o aluno a: conhecer os determinantes das desigualdades sociais como expressões da questão social; analisar o surgimento e a consolidação da profissão; adquirir habilidades necessárias à elaboração de trabalhos científicos e à vivência acadêmica; conhecer as formas de intervenção do Estado na questão social; conhecer as propostas de intervenção profissional; assumir postura ética com relação à ação profissional; desenvolver habilidades básicas para a intervenção profissional; conhecer os instrumentos da administração e do planejamento social; intervir nas várias áreas da política social; participar do processo de intervenção supervisionada e aprofundar as principais questões abordadas durante o curso através da reflexão dirigida e da elaboração de trabalho científico (UNIVERSIDADE ESTADUAL DE LONDRINA, 2009).

Já nessa primeira investigação, verificamos que as questões sociais são amplamente atualizadas no exercício desta profissão e sobre elas discorreremos mais adiante. Antes, porém, vale lembrar que, à medida que esse trabalhador atua em questões que são de cunho afetivo, ele também participa da produção de subjetividades, ou seja, intervêm diretamente na investigação e na invenção dos modos de vida e dos valores que circulam na comunidade. Reconhecemos aí a dimensão política que atravessa as atividades realizadas pelo Assistente Social.

Outro conjunto de informações pode ser encontrado na descrição sobre os objetivos do curso. Eles são assim definidos:

O bacharel em Serviço Social formado pela UEL deve ser um profissional: capaz de atuar na malha dos serviços sociais, formulando e implementando propostas para sua expansão e desenvolvimento, por meio de políticas sociais públicas, empresariais, de organizações da sociedade civil e dos movimentos sociais; dotado de formação intelectual e cultural generalista crítica, competente em sua área de desempenho, com capacidade de inserção criativa e propositiva, no conjunto das relações sociais e no mercado de trabalho; competindo com valores e princípios norteadores do Código de Ética do assistente social e habilitado a intervir através do uso adequado de estratégias, instrumentos e técnicas na relação direta com a população usuária de serviços sociais (UNIVERSIDADE ESTADUAL DE LONDRINA, 2009). 
Nota-se, diante dessas descrições, que um dos pontos centrais na formação do Assistente Social está em compreender a maneira como são criados e como funcionam os diferentes grupos sociais que compõe as comunidades, as instituições, as organizações estatais ou privadas, bem como os movimentos sociais de diferentes tipos. Com base nesse documento, percebe-se também que cabe a este profissional conhecer, de maneira competente, os processos de elaboração, de aprovação e de efetuação das políticas públicas vigentes em nosso país, uma vez que essa área de atuação nasce historicamente para colaborar com a gestão estatal.

\section{Analisando as dimensões afetivas atualizadas no trabalho do Assistente Social}

A partir dessas informações, podemos retomar a questão que deu forma a presente pesquisa: afinal, quais demandas afetivas são apresentadas para esses profissionais que dependem do contato social para realizar suas funções? Como a psicologia, voltada para a área do trabalho em sua interface com a área clínica, pode colaborar para compreender o sofrimento psíquico gerado nesse profissional?

Ao analisar o trabalho imaterial, Negri (2001, p. 28) considera que nele o profissional exprime-se "através das potências, das potências de viver, a que chamamos afetos. A vida afetiva se torna, portanto, uma das expressões da ferramenta de trabalho encarnada dentro do corpo". No trabalho afetivo, os profissionais estão em constante relação social e esse contato coopera para criar um campo comum no qual ocorrem misturas, composições, choques e enfrentamentos das mais variadas nuances.

Cada situação enfrentada por esse trabalhador, seja ela adversa ou favorável, colabora para fazer variar a potência de seu corpo, ora diminuindo ora aumentando sua vitalidade para estar com o outro. Não existe neutralidade, controle ou regularidade quando analisamos as atividades de tipo afetivo. Em cada um dos encontros vividos, o trabalhador é convocado a dar direção ao seu trabalho e a criar, dentro de cada situação, modos específicos de se portar e de se relacionar com a população que atende.

É precisamente imerso nessas misturas afetivas que o seu trabalho é executado. Deleuze, recorrendo a Espinosa, assinala que a investigação sobre a potência afetiva não pode ser concluída de maneira definitiva uma vez que "ninguém sabe antecipadamente os afetos de que é capaz" (DELEUZE, 2002, p. 130). Ele continua sua argumentação 
dizendo que as respostas ensaiadas sobre essa potência são sempre parciais uma vez que elas são conhecidas apenas a partir de uma "longa história de experimentação, uma demorada prudência" (DELEUZE, 2002, p. 130). Assim, fazer uma análise sobre o trabalho imaterial do Assistente Social necessariamente conduz a problematizações acerca da potência afetiva que é colocada em curso no cotidiano de seus encontros profissionais com a população atendida e com as situações que lhe são apresentadas. É nessa direção que caminharemos a partir desse momento de nosso estudo.

Primeiramente, é notável na descrição do curso, o quanto esse profissional transita entre dois universos que são distintos, mas amplamente relacionados. Por um lado, o assistente social é solicitado a ser um profundo conhecedor do aparato legal que é elaborado e aprovado de acordo com uma série de procedimentos instituídos pelos representantes do Estado. Esse conhecimento Ihe dá condições para analisar as diferentes situações nas quais o exercício da cidadania está comprometido. Por outro lado, ele também está em contato com o universo populacional, que se apresenta com problemas reais, tendo como pano de fundo, condições de existência por vezes difíceis e completamente fora das possibilidades de um amparo legal.

Sendo diferentes, e até contrastantes, esses dois universos enfrentam-se e, com isso, evidenciam as lacunas geradas na relação entre o cidadão e o Estado. As atividades profissionais atribuídas ao Assistente Social nascem precisamente dessa distância que, como tal, configura-se como seu principal campo de investigação, diagnóstico e intervenção.

A necessidade de transitar entre a legislação estatal (pautada nos procedimentos legais e nos saberes que são elaborados pelas diversas áreas de conhecimento como a medicina, a engenharia, a psicologia, a administração pública e o próprio serviço social) por um lado, e pelo saber popular (construído no cotidiano) por outro, justifica a criação e a permanência dessa área profissional. Assim, a sua atuação acontece a partir de uma espécie de luta onde comparecem as mais distintas forças. Que tipo de atenção essa luta exige? Pode-se dizer que esse profissional instala-se num campo problemático que solicita, a cada momento, uma habilidade política, mas também uma disponibilidade afetiva, para acolher e analisar cada problema que é colocado em pauta. 
Por ser um profissional que geralmente é contratado pelo Estado, a necessidade de ter como referência as políticas públicas, que muitas vezes são descontextualizadas e limitadas em relação à realidade social em questão, gera uma série de conflitos e paradoxos a serem por ele enfrentados. Analisando o trabalho imaterial, Gorz (2005) diz que no trabalho atual o sujeito é solicitado a apresentar soluções rápidas aos problemas geralmente inéditos que Ihe são apresentados. Segundo o autor, essa habilidade não pode ser conquistada apenas por meio de cursos técnicos ou universitários, mas ela envolve toda uma "bagagem cultural" que foi adquirida no decorrer da história de sua vida. Trata-se de um tipo de saber que é gerado no cotidiano das relações sociais e ativado a cada vez que o trabalhador depara-se com uma nova situação problema.

Gorz (2005, p. 19) ainda assinala que é nas atividades realizadas "fora do trabalho que são desenvolvidas sua vivacidade, sua capacidade de improvisação, de cooperação". É possível notar, então, o quanto a história de vida e a história afetiva do trabalhador, que foi construída majoritariamente fora do local de trabalho, produzem efeitos na maneira como ele realiza suas funções. Assim, no contexto do trabalho imaterial afetivo as experiências da vida privada muitas vezes entram em ressonância com os conteúdos aprendidos na formação universitária e com as experiências profissionais, sendo transportadas e ressignificadas para a resolução dos problemas enfrentados.

Um outro ponto a ser considerado é que estamos diante de um trabalhador que está cotidianamente em contato com conflitos, situações de marginalização e sofrimento humano, de desrespeito à lei e, por vezes, com a falta de leis que sejam compatíveis ao contexto populacional em que ele está atuando. A proximidade com as desigualdades sociais (que podem se materializar em situações limítrofes como a fome, o contraste de valores morais, higiênicos e organizacionais, enfermidades as mais distintas bem como as situações de violência) marca suas atividades, acentuando as dificuldades enfrentadas pela população atendida. Isso, por vezes, pode gerar uma sensação de impotência e o quase inevitável sofrimento psíquico. Há pouco vimos com Negri (2001) que a potência afetiva do trabalhador é a sua principal ferramenta. Dependendo da maneira como são vividas, estas situações podem diminuir a potência de ação tanto do profissional quanto daqueles com os quais ele trabalha. Daí a necessidade de manter uma espécie de 
prudência a partir da qual seja possível também tomar em apreciação os afetos experimentados e as repercussões que eles produzem no corpo desse trabalhador.

De diferentes maneiras, essa experimentação afetiva praticamente obriga o profissional a pensar, a planejar-se estrategicamente e a agir diante do problema que está em questão. Obviamente, o risco de frustração é iminente nessa profissão. Assim, todo um esforço é necessário para que suas ações sejam pautadas na análise rigorosa de cada situação, buscando compreender quais são as forças que nela estão colocadas e ponderar sobre as alternativas possíveis.

Pode-se dizer que, quanto mais as intervenções forem analisadas e planejadas, menos o profissional sofrerá os efeitos imediatos dos encontros. O risco, nesse último caso, é deixar-se afetar passivamente pelas situações, perdendo de vista o papel profissional que orienta suas ações (que, como dito na descrição do curso, está diretamente relacionado ao Estado, suas regras e sua velocidade) e, a partir daí, ver-se responsável por resolver, individual e imediatamente, problemas que são complexos e que, por isso mesmo, não admitem resoluções simples nem rápidas.

Cabe reafirmar ainda que no trabalho do assistente social o outro (que no caso pode ser compreendido como a população atendida ou mesmo os demais profissionais com os quais ele mantém-se em contato) comparece na relação de maneira muito viva, expressando seus desejos, dores, diferenças, conflitos, limites e potencialidades. E, dependendo da situação a ser analisada, as necessidades populacionais nem sempre são compatíveis com a temporalidade das leis, com as exigências dos saberes especializados ou com os recursos disponíveis para atendê-las. Isso gera uma série de dificuldades, demandando novamente uma habilidade política para transitar entre as diferenças e as possibilidades.

Analisando as variações de potência afetiva que são experimentadas por esse trabalhador, pode-se dizer que as atividades por ele realizadas nem sempre ficam restritas à sua carga horária contratual. Como o corpo afetável é um de seus maiores instrumentos de trabalho, as experiências vividas no contato com essa população díspar, possivelmente, irão reverberar e produzir efeitos nas relações experimentadas para além do trabalho. Pode-se dizer que nessa profissão, a separação entre a vida profissional e a vida privada tem seus contornos e seus limites praticamente esfumaçados. Tendo seu 
corpo afetado por uma realidade social contraditória e complexa, e ainda precisando elaborar os afetos que emergem a partir desses encontros, a jornada de trabalho tende a estender-se para aquelas atividades ligadas à vida privada como, por exemplo, o tempo livre, a sociabilidade, as relações amorosas e a vida familiar.

Retomando um outro aspecto das descrições sobre o curso de Serviço Social, vemos que as tarefas de "formular e implementar propostas" de atuação na malha social solicita esse profissional, de maneira recorrente, para a criação de alternativas e soluções. Assim, uma outra dimensão afetiva pode ser aqui assinalada: aquela que o convoca para a solução de problemas. Novamente ressaltamos que, dependendo de como essa tarefa é acolhida, a jornada de trabalho pode não ser suficiente para delimitar suas atividades. Cabe dizer que essa "invasão da vida privada" não é contornada por uma simples deliberação da consciência do tipo: "A partir de agora o trabalho acabou". No exercício do trabalho imaterial esse tipo de decisão fica praticamente suspenso uma vez que o corpo e sua potência foram afetados e convocados para agir, problematizar e criar alternativas.

Vemos, portanto, que a produção imaterial é sustentada por um alto grau de investimento desejante, ainda que, como já dissemos anteriormente, as dificuldades caminhem lado a lado com as soluções e conquistas.

A presença do risco é outra dimensão atualizada no cotidiano laboral do Assistente Social. O risco pode vir acompanhado da angústia gerada pelo medo de errar, pelo receio de sofrer as consequências advindas de uma intervenção, ou mesmo pela preocupação de não corresponder às expectativas que Ihe foram depositadas tanto pelo empregador quanto pelo público atendido, num contexto cujo traço dominante é a contradição. Ressaltamos que nesse tipo de atuação profissional, uma conduta tomada não pode ser avaliada de maneira isolada. Ela está sempre posicionada num conjunto múltiplo e complexo de elementos e agentes sociais. Ao mesmo tempo, qualquer intervenção depende de condições políticas e financeiras que são variáveis e, por vezes, limitadas.

Nesse sentido, consideramos que quando o profissional toma para si a responsabilidade "total" pela resolução "definitiva" de uma dada situação-problema, a onipotência e o medo podem se consolidar como o maior risco. Mas, como não vivê-los num tempo histórico que não só individualiza as ações como também responsabiliza o indivíduo pelos resultados alcançados? Trata-se de uma época onde o "declínio do 
homem público", conforme estudado por Richard Sennett (1998), está consolidado e produz efeitos que repercutem nas relações sociais e profissionais. Obviamente, o assistente social não está isento desse risco.

Negri e Hardt (2001) falam ainda sobre a existência de um outro elemento fundamental, de cunho afetivo, que comparece no estudo desse tipo de trabalho: trata-se da capacidade de cooperação. O assistente social é um profissional que atua frequentemente em parceria com outras profissões. Essa interação e troca sustentam o caráter social, comunicativo e dialógico de suas atividades. Hardt e Negri (2001, p. 315) consideram que isso pode vir a aumentar a potência dos agentes, visto que o

trabalho imaterial envolve de imediato a interação e a cooperação sociais. Em outras palavras, o aspecto cooperativo do trabalho imaterial não é imposto e organizado de fora, como ocorria em formas anteriores de trabalho, mas a cooperação é totalmente imanente à própria atividade laboral.

Pela cooperação, tal qual compreendida pelos autores, é possível tomar contato com conhecimentos e habilidades variadas que são utilizadas de maneiras e em graus distintos pelos profissionais. Assim, por meio das inúmeras conexões, trocas e debates entre os trabalhadores, a elaboração de propostas pode ser mais enriquecida. Da cooperação e dos processos de aprendizagem colocados em curso nessas trocas, o trabalhador pode experimentar uma relação diferenciada com suas atividades cotidianas e com os demais indivíduos que dela participam. A cooperação entre os profissionais pode produzir uma análise conjunta dos problemas a serem enfrentados a partir de diferentes ângulos e áreas de conhecimento, evitando assim, ações meramente individuais que, por vezes, geram isolamento.

Deparamo-nos, então, com uma outra característica do trabalho imaterial: a dificuldade, e até a impossibilidade, de mensurar os resultados gerados por suas intervenções. Tradicionalmente, a avaliação dos resultados obtidos na produção material é quantitativa, ou seja, ao final de um dia de produção é possível, ao trabalhador e ao empregador, saber numérica e objetivamente quais foram os resultados alcançados. Entretanto, torna-se impossível transferir o instrumento quantitativo para averiguar os resultados do trabalho afetivo. 
Cada intervenção realizada por um assistente social envolve um conjunto complexo de elementos e pessoas que se misturam, se rearticulam e se transformam num movimento que é marcado pela construção coletiva. Isso impede a discriminação precisa da intervenção de cada um dos envolvidos. Assim, o acesso e mesmo a mensuração dos resultados é algo que não pode ser facilmente visualizado, pois envolve a construção de soluções parciais cujo resultado depende de uma temporalidade que, por vezes, é inacessível ao profissional. Essa peculiaridade, uma vez desconsiderada, pode gerar angústia diante da dificuldade de acesso do profissional aos resultados de seu trabalho, visto que eles se perdem no fluxo das histórias das pessoas que são por ele atendidas e que seguem suas vidas dificultando as possibilidades de um contato futuro.

\section{Considerações finais}

A essa altura de nossa análise já é possível atentarmos para algumas psicopatologias que emergem no exercício do trabalho imaterial. Não é por acaso que diversas iniciativas de investigação sobre a saúde do trabalhador vêm ganhando espaço na contemporaneidade como, por exemplo, as pesquisas sobre a saúde mental (DEJOURS, 1992). Submetido a um alto grau de exigência, competição e de produtividade, cresce o número de licenças solicitadas por trabalhadores que alegam estar passando por quadros psicopatológicos sérios como o stress, a depressão e o pânico. Cada uma dessas patologias tem manifestação variada entre os trabalhadores. Assim, o que nos interessa assinalar aqui é que esses sintomas não estão ligados a um funcionamento psíquico meramente individual. Eles são construídos no cotidiano das relações laborais e, por vezes, são frutos de exigências intelectuais e afetivas, diante das quais o corpo esgotado responde adoecendo. Sueli Rolnik destaca que essas adversidades vividas pelo trabalhador precisam ser compreendidas de maneira mais contextualizada, uma vez que abarcam os

sintomas de uma civilização, a do capitalismo mundial integrado, com ramificações por toda a trama da existência humana, da política à economia passando pela cultura e, evidentemente pelos modos de subjetivação. Este é um ponto de vista distinto daquele construído pela psiquiatria e amplamente estimulado pela indústria farmacológica, que consiste em reduzir tais sintomas a quadros nosológicos de uma psicopatologia ou de uma neurologia, perdendo de vista a complexa trama de cada subjetividade em que se apresentam (ROLNIK, 2003, p. 7). 
Como essa trama social e histórica se consolida nas atividades do assistente social? O alto grau de frustração, o contato com situações de sofrimento que colocam em risco a vida de um contingente populacional, a dependência de procedimentos burocráticos lentos bem como o risco iminente de que uma dada intervenção não traga os resultados esperados, fazem parte do cotidiano desse profissional.

Essa cadeia produtiva gera o sofrimento, a despotencialização e a dor psíquica que tendem a enfraquecer sua potência para agir. Apesar disso, é diante desses afetos que o profissional dará direção ao seu trabalho e criará, dentro de cada situação, modos específicos de se portar e de se relacionar com a população atendida. Daí o caráter inédito de suas intervenções que poderão ser conhecidas apenas no contato desse trabalhador com as intensidades que são vividas por ocasião de cada novo encontro. Cabe destacar, então, que os contatos afetivos experimentados no cotidiano laboral não são neutros, mas carregados de sensações e intensidades. De diferentes maneiras, essa experimentação participa da resolução dos problemas. Assim, as tomadas de decisão serão sempre variáveis entre os trabalhadores e na trajetória profissional percorrida por um mesmo trabalhador. Estamos diante de um tipo de trabalho que guarda um grau de imprevisibilidade permanente, fato que torna o seu exercício ainda mais dinâmico. Seja qual for o caminho encontrado para enfrentar essas adversidades, o corpo e a potência afetiva interferem no processo e são primordiais.

É nesse sentido que ressaltamos, já numa síntese parcial dessa investigação, que atentar para essa variação da potência torna-se um dos maiores desafios dessa prática profissional. Assim, dedicar uma atenção a si mesmo, acompanhando e analisando as variações de potência vividas no próprio corpo possibilita que, aos poucos, esse profissional torne-se capaz de transitar, de maneira mais aberta, pelos diferentes contextos e pelos diferentes problemas que o convocam a pensar, a criar e, por fim, a reconhecer os limites e as chances de intervenção no social. Mas, principalmente, consiga reconhecer a importância de tomar em consideração as inúmeras forças que compõem cada situação analisada.

Ao acolher a dimensão política que atravessa sua profissão, o assistente social poderá analisar também os afetos que emergem no seu cotidiano e fazer com que sua prática seja um exercício de invenção, experimentação e intervenção. Afinal, sua 
atividade profissional volta-se para o que é vivo, pulsa e transforma-se. E sobre isso não há possibilidades de previsão ou controle. É possível contar, basicamente, com formação acadêmica, os saberes construídos no cotidiano e, em especial, com a potência do corpo para percorrer as diferentes realidades sociais que sempre trarão uma dimensão inédita e inesperada.

\section{Referências}

DEJOURS, C. A Loucura do trabalho: estudos de psicopatologia do trabalho. São Paulo: Cortez, 1992.

DONZELOT, J. A Polícia das famílias. Rio de Janeiro. Edições Graal, 1980.

DELEUZE, G. Espinosa: filosofia prática. São Paulo: Escuta, 2002.

FOUCAULT, M. A Verdade e as formas jurídicas. Rio de Janeiro: Nau Ed., 1999.

NEGRI, A.; HARDT, M. Império. Rio de Janeiro: Record, 2001.

LAZZARATO, M.; NEGRI, A. Trabalho Imaterial: formas de vida e produção de subjetividade. Rio de Janeiro: DP\&A, 2001.

GORZ, A. O Imaterial: conhecimento, valor e capital. São Paulo: Annablume, 2005.

ROLNIK, S. "Fale com ele" ou como tratar o corpo vibrátil em coma. Disponível em $<w w w . c a d e r n o s d e s u b j e t i v i d a d e . p u c s p . b r>$ Acesso em: 15 dez. 2008.

SENNETT, R. O Declínio do homem público: tiranias da intimidade. São Paulo: Companhia das Letras, 1998.

UNIVERSIDADE ESTADUAL DE LONDRINA. Pró-Reitoria de Graduação. Catálogo de Cursos 2009: serviço social. Londrina, 2009. Disponível em <http://www.uel.br/prograd/ catalogo-cursos/catalogo_2009/informacoes_cursos/servico_social.pdf>. Acesso em 20 ago 2009. 